\title{
APPLYING THE STRAIN ENERGY DENSITY CRITERION TO FATIGUE AND FRACTURE PROBLEMS IN THE TRANSPORTATION INDUSTRY
}

\author{
David Y. Jeong
}

\begin{abstract}
Today fracture mechanics is an independent discipline that deals with structures containing detectable or visible sharp cracks. The basic concepts of fracture mechanics are well established due to the contributions of researchers such as G. C. Sih. This paper focuses on one of his many contributions; specifically, the strain energy density criterion for fatigue and fracture problems involving mixed mode loading. Moreover, this paper reviews examples of original research in the transportation industry in which the strain energy density criterion was applied. In particular, these examples come from the aircraft and railroad industries. Both industries now use fatigue and fracture control programs, developed from damage tolerance or fracture mechanics principles, to minimize the risks associated with structural failures.
\end{abstract}

\section{Key Words:}

\section{INTRODUCTION}

Historically, the problems associated with fatigue and fracture have been brought to the forefront of research after the occurrence of a structural failure. For example, brittle fractures were observed in about twenty-five percent of the fleet of welded Liberty ships constructed in the United States in the 1940s. Investigations revealed that the maximum bending moments at the time of failure were one-half of the bending moments allowed for in the design. Subsequently much of the early work on fracture mechanics in the United States was conducted at the Naval Research Laboratories. In 1954, the Comet I aircraft, the first jet-propelled passenger airplane, disintegrated in the air at approximately 9,140 meters (30, 000 feet) and crashed into the Mediterranean Sea near Elba. Investigation of this crash concluded that the accident was caused by fatigue failure of the pressurized cabin. In 1988, an explosive decompression occurred in a commercial transport aircraft when approximately 5.5 meters (18 feet) of the upper crown

*D. Y. Jeong is with the U.S. Department of Transportation, Research and Special Programs Administration, Volpe National Transportation Systems Center, Cambridge, MA 02142, USA. (Email: jeong@volpe.dot.gov) skin and structure separated from the fuselage while in flight at about 7,320 meters (24,000 feet) near Maui, Hawaii. The failure was caused by the formation, growth, and linkup of multiple fatigue cracks. The phenomenon of multiple site fatigue cracking in aging airplanes is now referred to as "widespread fatigue damage."

Today the principles of fracture mechanics are applied during the design process to control, mitigate, or prevent structural failures due to fatigue and fracture. Moreover, the basic concepts of fracture mechanics are now well known and established due to the contributions of researchers such as G. C. Sih. One among his many contributions is the development of the strain energy density criterion for fatigue and fracture problems involving mixed mode loading (Sih, 1974).

This paper reviews four examples in the transportation industry in which the strain energy density criterion was applied to examine the fatigue and fracture process. These examples originate from previous research studies. Two examples are presented from the aircraft industry, and are specifically related to the phenomenon of widespread fatigue damage. The other two examples come from the railroad industry, which now is evolving its fatigue and fracture control programs to emulate the damage 


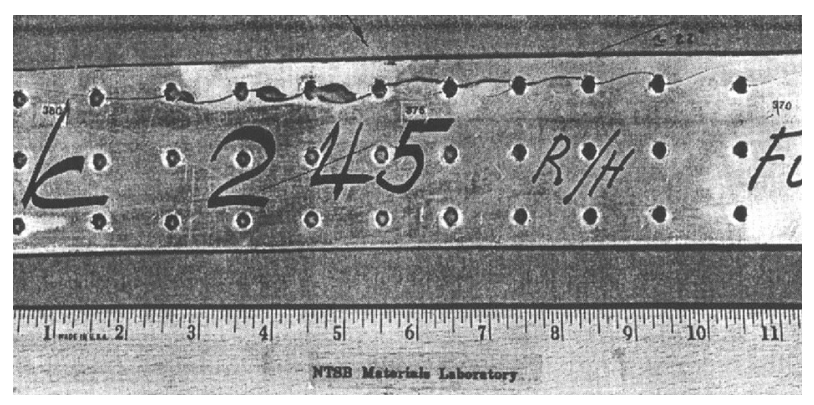

Fig. 1 Photograph of widespread fatigue damage in actual fuselage lap splice

tolerance approach originally developed and now embraced by the aircraft industry. The specific details of the strain energy density criterion are left out of this paper, but can be found in the open literature (e.g., Sih, 1974; 1976).

\section{AIRCRAFT FUSELAGE}

Multiple site cracking is known to occur in aging airplanes in the upper rivet row of the lap splice joint located near the fuselage crown. These fatigue cracks propagate at an inclined angle rather than purely horizontal, implying that the fuselage lap joint is subjected to mixed mode loading. The source of mixed mode loading is biaxial stress due to cabin pressurization and transverse shear due to body bending of the fuselage. Fig. 1 is a photograph of multiple site cracking discovered in a fuselage lap splice during an inspection of the fleet following the dramatic structural failure in 1988.

\section{Mixed Mode Fatigue Crack Growth}

The strain energy density criterion was applied to examine the mixed-mode fatigue crack growth of inclined cracks emanating from an open hole in tensile test coupons (Jeong, 2004). The coupons were made from 2024-T3 aluminum, and contained an open hole in the center with a diameter of $4.83 \mathrm{~mm}(0.19$ in) and with inclined cracks emanating from its periphery at an angle of $20 \mathrm{E}$ from the horizontal. The initial length of the radial cracks was $2.54 \mathrm{~mm}(0.1$ inches). In addition, an engineering approximation was used to model a curved crack as a straight crack of equal stress intensity (Sih and Barthelemy, 1980). Fig. 2 compares the results from the strain energy density analysis with measured crack trajectories after 20,000 fatigue cycles were applied.

In an actual aircraft, the rivet applies pressure inside the hole, which may affect the crack trajectory as it grows under fatigue loading. Although the testing and analysis were performed on a coupon with an

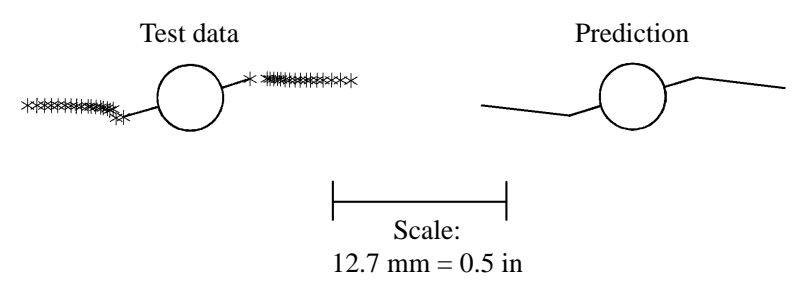

Fig. 2 Comparison of crack trajectories predicted by strain energy density criterion and test data

open hole, the predicted crack trajectories appear to resemble the curved cracking pattern that is characteristic of widespread fatigue damage.

\section{Stable Tearing of Multiple Cracks}

Experiments on open-hole tensile coupons with hole diameter and spacing similar to typical aircraft construction details have also shown that stable crack extension occurs prior to fracture of the specimen. Elastic-plastic finite element analyses were carried out to predict the stable crack extension and failure by plastic collapse. Moreover, the incremental theory of plasticity was used in conjunction with the strain energy density criterion (Jeong et al., 1995).

Although the criterion was originally developed and applied to linear elastic materials, it was later found to be applicable to ductile fracture as well (Sih and Madenci, 1983; Sih and Chen, 1985). The extension to ductile fracture is founded on a property of the strain energy density function. It is well known that, inside the plastic zone surrounding the crack tip, the asymptotic stresses and strains deviate from the $\sqrt{r}$-singularity that characterizes the elastic distributions. However, the strain energy density function retains the $1 / \mathrm{r}$-singularity independent of the constitutive equation.

Tensile tests were conducted on coupons made from sheets of clad 2024-T3 aluminum, $101.6 \mathrm{~mm}$ (4 inches) in width by $1.02 \mathrm{~mm}$ (0.04 in) in thickness. The coupons contained a row of three drilled holes $4.67 \mathrm{~mm}(3 / 16 \mathrm{in})$ in diameter with $25.4 \mathrm{~mm}$ (1.0 inch) center-to-center spacing. The center hole was symmetrically notched, and fatigue loads were applied to produce sharpened cracks. The inner edges of the outer holes were then notched to produce the initial configuration for the experiment (Fig. 3). Three initial crack lengths $a_{0}$ were tested: $3.81,5.59$, and 6.60 $\mathrm{mm}(0.15,0.22$, and $0.26 \mathrm{in})$.

The results of the strain energy density analysis are compared with the experimental results in Fig. 4. Solid and open symbols represent the analytical and experimental results respectively. Lines between data points have been included for visual guidance, and have no physical or numerical meaning. The 


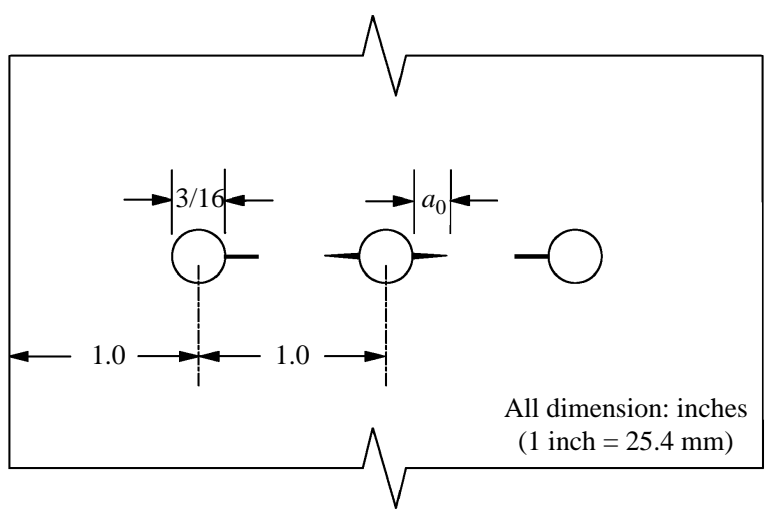

Fig. 3 Initial configuration of test coupons for experiments on stable crack extension

agreement between the calculated and experimental crack extensions is reasonable but not precise. The lack of better agreement may be due to experimental error in the visual measurement of crack extension, approximations made in the numerical stress analysis, or both.

The analysis in this example demonstrates the application of the strain energy density criterion to calculate stable extension of multiple Mode I cracks in ductile material. Moreover, the strain energy density approach provides a logical approach to damage tolerance evaluation of multiple cracking in structures where mixed mode loading prevails and where the stability limit may be either controlled by plastic collapse or on the borderline between plastic collapse and ductile fracture.

\section{RAILROAD RAILS}

A recent study of accident statistics compiled by the Federal Railroad Administration, an agency within the U.S. Department of Transportation, indicates that internal rail defects and defects in rail joints account for over 40 percent of the damage resulting from derailments caused by broken rails (Jeong, 2001).

\section{Rail Head Defects}

In October 2000, a train traveling at approximately 69 kilometers per hour (115 miles per hour) derailed near Hatfield in Great Britain, killing four people and injuring 70 others. An investigation conducted by Britain's Health and Safety Executive (HSE) determined that the derailment was caused by a broken rail originating from an internal defect in the rail head.

In March 2001, an Amtrak train consisting of two locomotives and 16 passenger cars derailed near

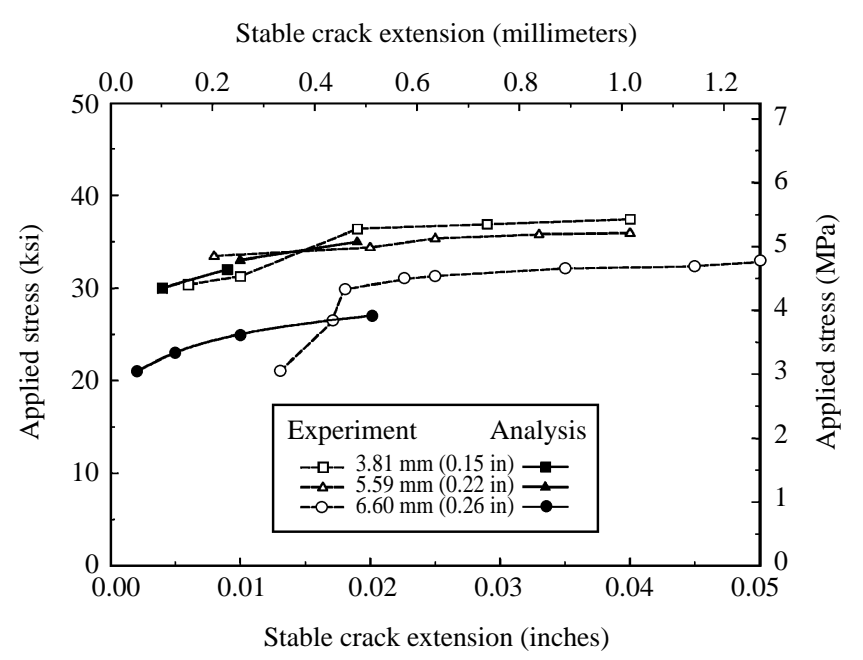

Fig. 4 Comparison of results from experiments and analysis

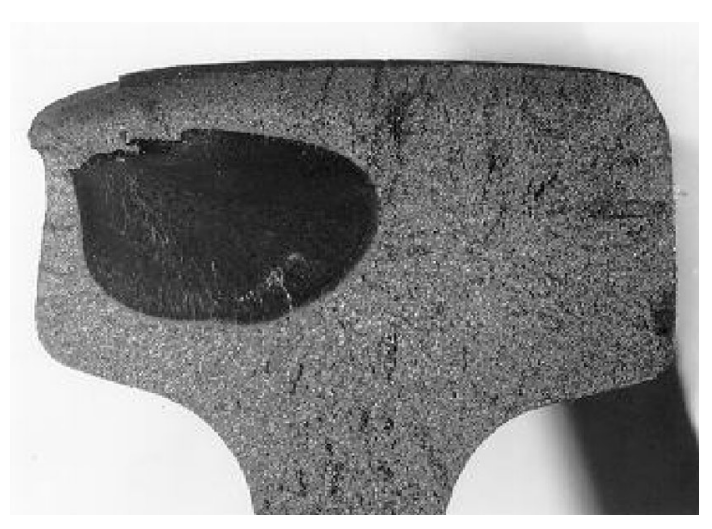

Fig. 5 Photograph of actual rail head defect

Nodoway, Iowa in the United States. As a result of the derailment, 78 people were injured, including 1 fatal injury. An investigation of the accident by the National Transportation Safety Board (NTSB) determined that the probable cause of the derailment was rail failure beneath the train due to undetected internal defects. Fig. 5 shows a photograph of this particular type of internal rail head defect, which is called a detail fracture.

A three-dimensional elastic finite element analysis was used in conjunction with the strain energy density criterion to predict the growth pattern of a detail fracture (Sih and Tzou, 1984). The detail fracture was represented initially by a circular crack embedded in the rail head, and the strain energy density criterion was used to calculate the rate of crack growth and the change of crack shape. Fig. 6 shows the growth pattern calculated from the analysis, assuming one stress cycle per wheel load. Although the analysis neglected residual and thermal stresses, the calculated crack growth lives were of the same order 


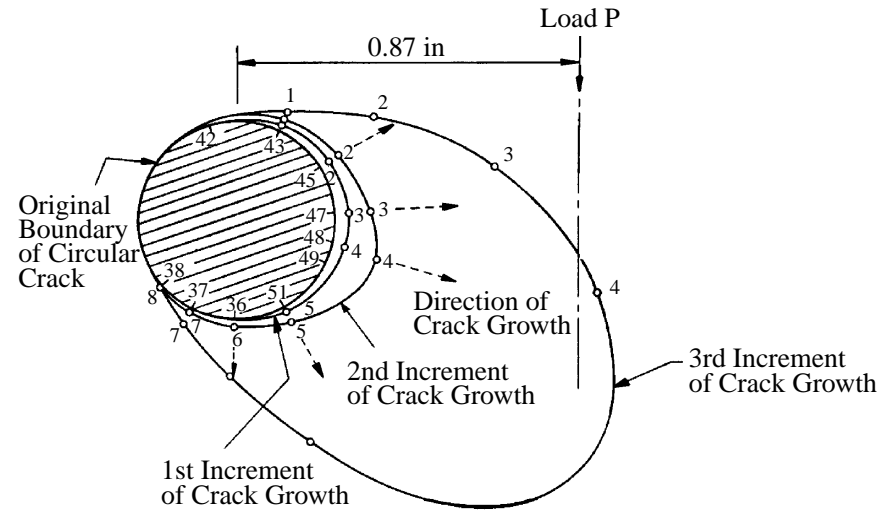

Fig. 6 Growth of rail head defect predicted by strain energy density criterion (Sih and Tzou, 1984)

as those observed in service, and the crack shape appears to follow the evolving shape of a detail fracture.

A recent study of broken rails from undetected rail head defects suggests that the three-dimensional character of such defects affects how reliably current ultrasonic technology can find them (Garcia et al, 2003). The analysis in this example considered only Modes I and III (i.e., opening and tearing modes of fracture). Moreover, a conclusion from this example is that the three-dimensional character of rail defects, such as detail fractures, can be traced by using the strain energy density criterion and assuming all three modes of fracture (i.e., opening, sliding, and tearing modes).

\section{Bolt-Hole Defects}

In March 1996, more than 3,000 people were evacuated in Weyauwega, Wisconsin in the US when seven tank cars filled with liquid propane gas derailed and caught fire. The cause of the derailment is believed to have been a broken switch-point rail, which originated from an undetected bolt-hole crack.

Bolt-hole cracks account for about half of the rail defects in jointed track in North America. They originate in rail joints at the corners between the rail web and the surface of the bolt hole. Bolt-hole cracks generally emanate from the hole closest to the rail end at about a 45E angle, and grow until the crack reaches the rail head or base (Fig. 7). Formation of bolt-hole cracks is believed to result from fretting fatigue when the shank of the bolt bears against the surface of the hole in a loose joint.

A three-dimensional finite element analysis of bolt-hole cracks in rail was performed in conjunction with the strain energy density criterion to determine the branching and trajectories of the cracks emanating from the bolt hole (Sih and Tzou, 1985). The

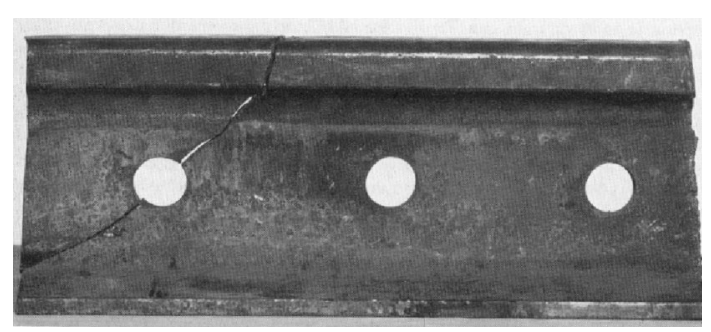

Fig. 7 Bolt-hole crack in rail

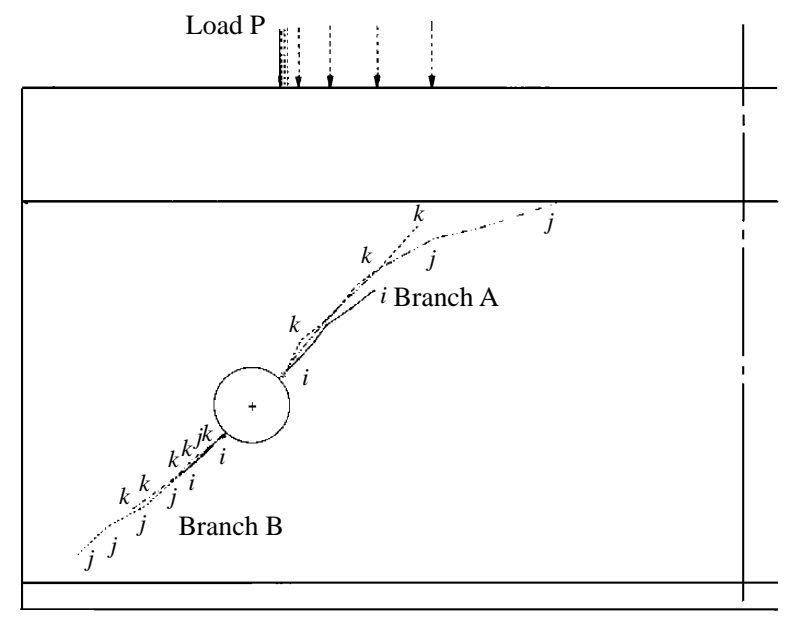

Fig. 8 Path of bolt-hole crack predicted by strain energy density criterion (Sih and Tzou, 1985)

results of the analysis suggest that bolt-hole cracking causes rail failure by propagating and penetrating into the rail head before reaching the base. Moreover, the predicted crack trajectories resembled those from actual rail-end fragments (Fig. 8).

The growth of bolt-hole cracks has not been studied as thoroughly as that of detail fractures, in part because of the increasing trend in the railroad industry to replace bolted joint rail with continuous welded rail. Consequently, detail fractures are expected to be the predominant defect encountered in rail in the future.

\section{CONCLUDING REMARKS}

Basic research entails the observation of problems, solution of such problems by hypothesis and collection of evidence, and communication of results. This paper showed examples of this research cycle in the context of fracture and fatigue problems in the transportation industry, with a particular focus on the strain energy density criterion developed by G.C. Sih. The resemblance of the predicted and actual crack shapes and trajectories shown in the examples in this paper provides a high level of confidence in the fracture mechanics approach in treating 
such problems. Although significant progress has been achieved to enhance the current understanding of fracture mechanics, additional research will always be needed to meet future challenges.

\section{ACKNOWLEDGMENTS}

The author studied under Professor G.C. Sih at the Institute of Fracture and Solid Mechanics. He graduated from Lehigh University with a Ph.D. in applied mechanics. The experience was rewarding more than professionally; the author met his wife during this time at Lehigh.

\section{REFERENCES}

Garcia, G., Snell, M. E., Davis, D. D., Trevizo, M. C., and Plotkin, D., 2003, "Flaw Characterization of Rail Service Failures," Report No. R963, Association of American Railroads.

Jeong, D. Y., 2001, "Progress in Rail Integrity Research," Volpe Center Final Report, DOT/FRA/ ORD-01/18.

Jeong, D. Y., 2004, "Mixed Mode Fatigue Crack Growth in Test Coupons Made from 2024-T3 Aluminum," Theoretical and Applied Fracture Mechanics (in press).

Jeong, D. Y., Orringer, O., and Sih, G.C., 1995, "Strain Energy Density Approach to Stable Crack Extension under Net Section Yielding of Aircraft Fuselage," Theoretical and Applied Fracture
Mechanics, Vol. 22, pp. 127-137.

Sih, G. C., 1974, "Strain Energy Density Factor Applied to Mixed Mode Crack Problems," International Journal of Fracture, Vol. 10, pp. 305-322.

Sih, G. C., 1976, "The Role of Fracture Mechanics in Design Technology," Journal of Engineering for Industry, pp. 1243-1249.

Sih, G. C., and Barthelemy, B. M., 1980, "Mixed Mode Fatigue Crack Growth Predictions," Engineering Fracture Mechanics, Vol. 13, pp. 657666.

Sih, G. C., and Chen, C., 1985, "Non-Self-Similar Crack Growth in Elastic-Plastic Finite Thickness Plate," Theoretical and Applied Fracture Mechanics, Vol. 3, pp. 125-139.

Sih, G. C., and Madenci, E., 1983, "Fracture Initiation under Gross Yielding, Strain Energy Density Criterion," Engineering Fracture Mechanics, Vol. 18, pp. 667-677.

Sih, G. C., and Tzou, D. Y., 1984, “Three-Dimensional Transverse Fatigue Crack Growth in Railhead," Theoretical and Applied Fracture Mechanics, Vol. 1, pp. 103-115.

Sih, G. C., and Tzou, D. Y., 1985, "Rail-End Bolt Hole Fatigue Crack in Three Dimensions," Theoretical and Applied Fracture Mechanics, Vol. 3, pp. 97-112.

Manuscript Received: May 28, 2004 and Accepted: Jul. 02, 2004 